\title{
Geophysical investigation across the Peel boundary fault (The Netherlands) for a paleoseismological study
}

\author{
D. Demanet ${ }^{1}$, L.G. Evers ${ }^{2}$, H. Teerlynck ${ }^{1}$, B. Dost \& D. Jongmans ${ }^{1,3}$
}

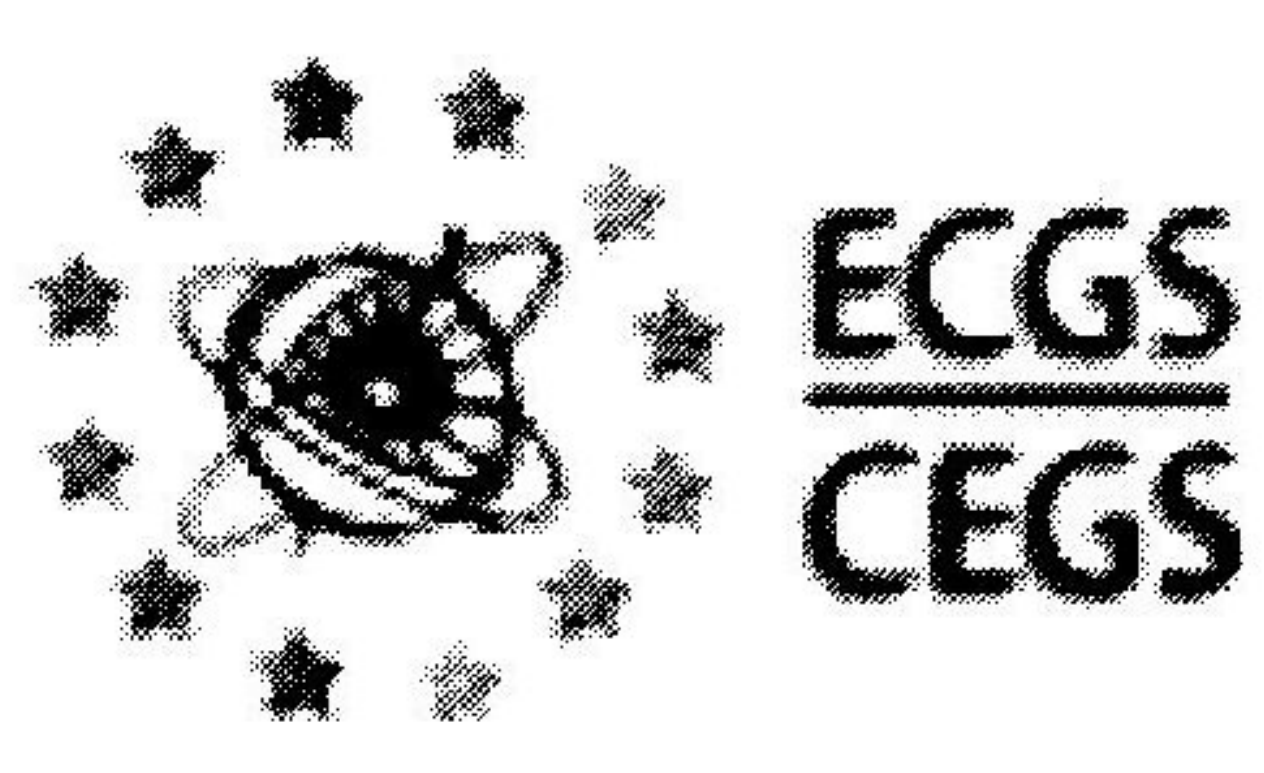

1 LGIH Université de Liège, Bat B19, B-4000 Liège, Belgium; e-mail: h.teerlynck@ulg.ac.be

2 Royal Netherlands Meteorological Institute (KNMI), PO Box 201, 3730 AE De Bilt, The Netherlands; e-mail: evers@knmi.nl

3 LIRIGM Université Joseph Fourier-Grenoble 1, BP 53-F 38041 Grenoble Cedex 9, France; e-mail: denis.jongmans@ujf-grenoble.fr

Manuscript received: July 2000; accepted: April 2001

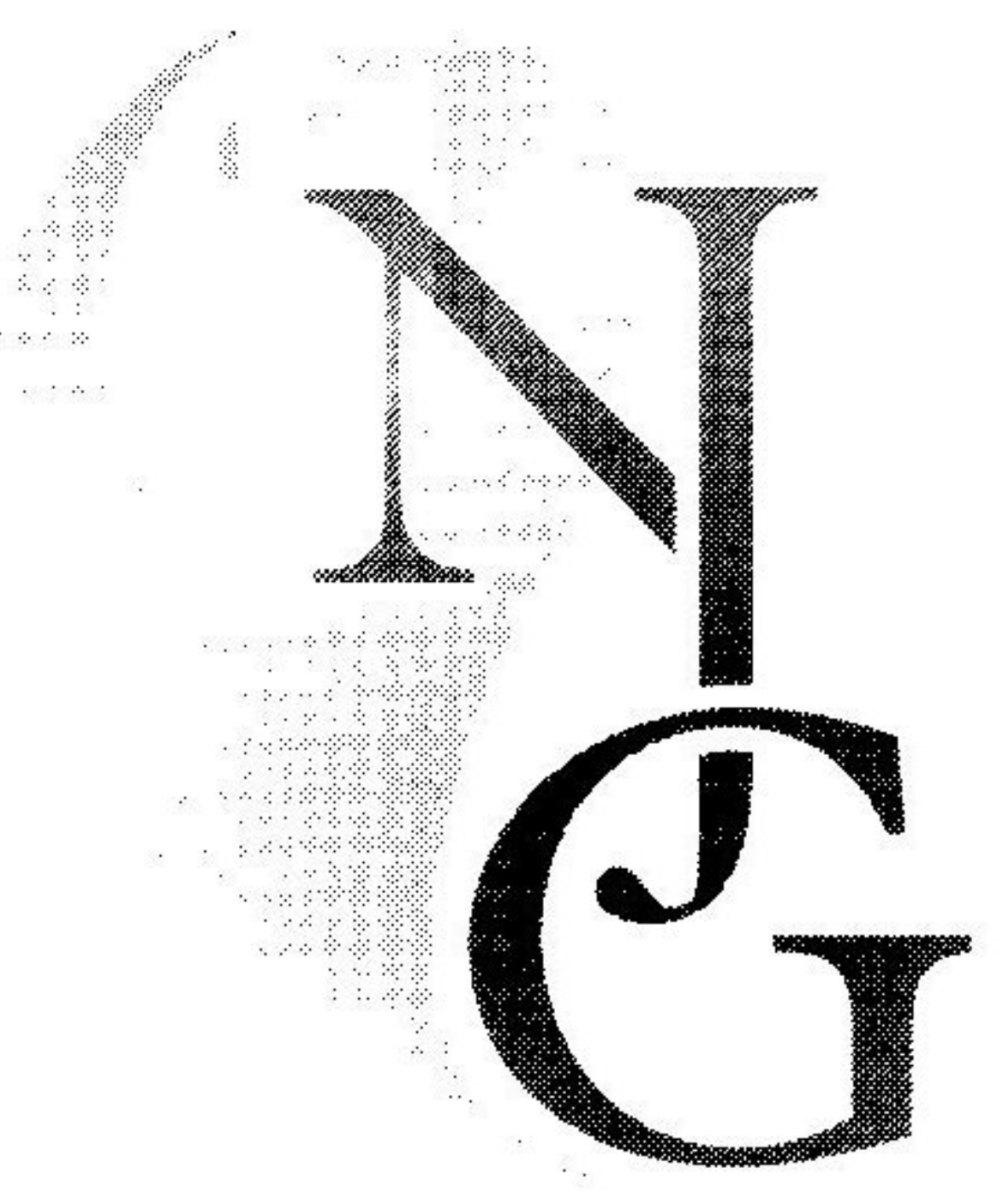

\begin{abstract}
In preparation of the first paleoseismic trenching in the NE border of the Roer graben (the Netherlands), site selection was carried out. Combining geological and seismological information and using existing aerial photographs, seismic reflection and geodetic levelling data, it was decided to focus on the Peel boundary fault near the village of Neer. Detailed information on the exact location of the fault was obtained through geophysical techniques, mainly ground penetrating radar (GPR) and resistivity measurements. GPR data unambiguously showed the flexuring and offset of reflectors affected by the fault. Performing eleven GPR profiles along strike allowed to obtain a 3D picture of the fault, laterally extending the information given in the trench.
\end{abstract}

Keywords: paleoseismology, Roer graben, geophysical prospecting

\section{Introduction}

This study is a part of the European Community project PALEOSIS (ENV4-CT97-0578) whose main objective is the evaluation of the potential for large earthquakes in regions of present day low seismic activity. A major aim of this project was the use of geophysical prospecting for locating faults before trenching and for imaging them at depth inaccessible to trenching. Several areas were considered in the project, one of them being the Dutch part of the Lower Rhine Embayment. In this area, it was decided to focus on the Peel boundary fault which is the Northeastern bordering fault of the Roer Valley Graben (fig. $1)$.

This fault is one of the main active tectonic features in the Netherlands and has shown in recent times a moderate earthquake (Roermond 13-4-1992, $\mathrm{M}_{\mathrm{L}}=$ 5.8). Movements along the Peel boundary fault are reflected by the change in sedimentary thickness across the fault (Geluk et al., 1994). During the Pliocene and Quaternary, sedimentation became increasingly restricted to the Roer Valley Graben. The Pliocene and Quartenary sediments reach a thickness of 300 and $200 \mathrm{~m}$, respectively, and are limited almost entirely to the Graben (Zagwijn, 1989). The site at Neer is situated on a Maas river fill terrace made of sands and gravel-rich sands (van den Berg, 1996). The $4 \mathrm{~m}$ deep trench was dug in fine grained sands showing a transition from fluvial deposits at the bottom to aeolian bedding at the top (van den Berg et al., in preparation)

A wide range of geophysical methods exists (seismic refraction and reflection profiles, electrical methods, electromagnetic surveying, ground penetrating radar, gravimetry, magnetic survey, which are sensitive to different physical properties. The major concern about these methods generally lies in the pene- 


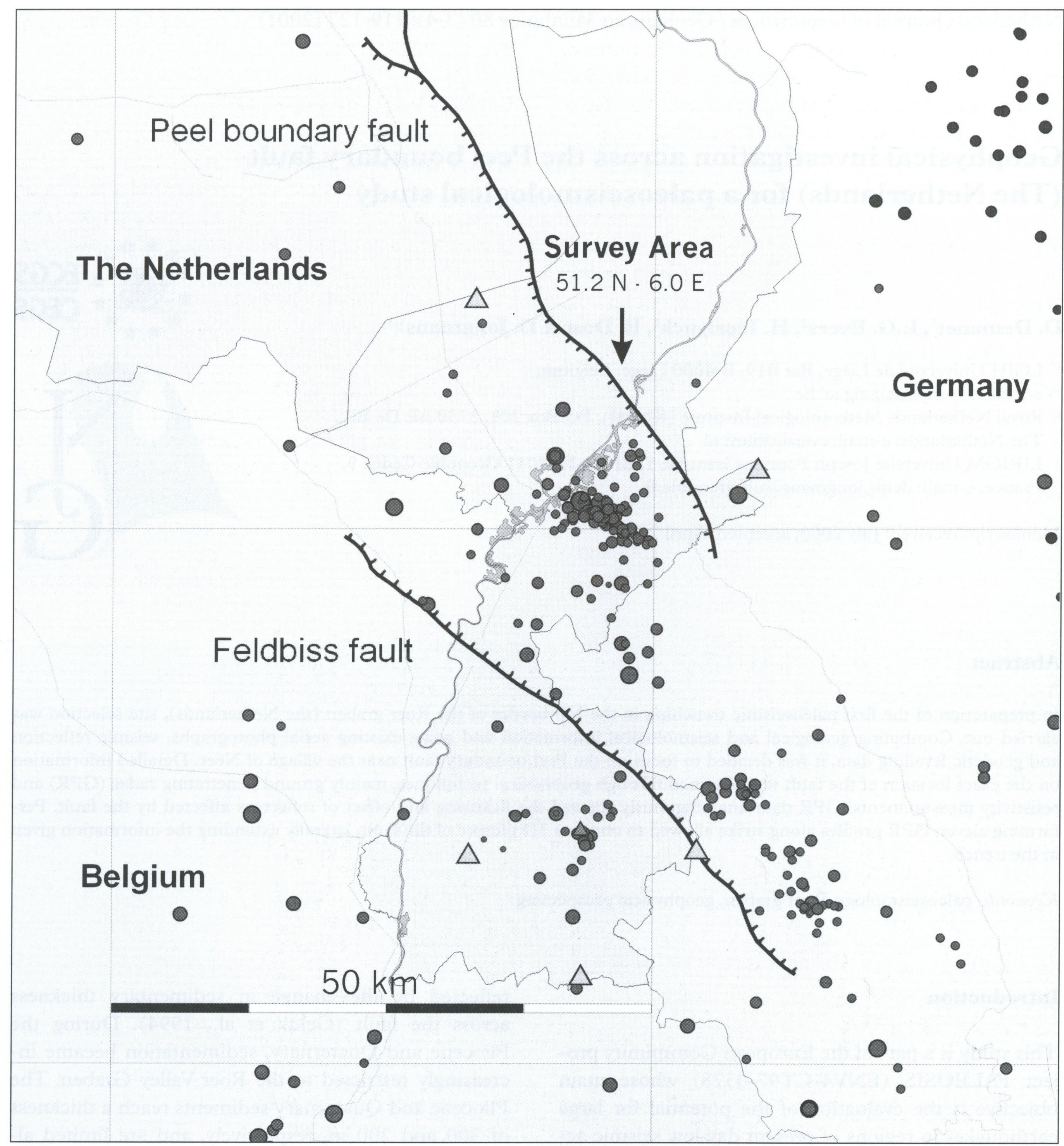

Fig. 1. Overview of seismicity in the Netherlands and surrounding region (1980-2000). The Peel boundary fault is the north-eastern boundary of the Roer Valley Graben while the Feldbiss fault bounds it to the South-west. The dots represent earthquakes and the triangles denote seismological stations.

tration and in the resolution. The penetration is the depth of the deeper body or layer which that still influences the geophysical measurements. The resolution is defined as the smallest size a structure must have to be detectable. These two characteristics are almost always antagonistic: the greater the penetration depth, the lower the resolution and vice versa (Reynolds, 1997).

Geophysical prospecting has already been applied in paleoseimological studies; but was however limited to one specific technique, generally high-resolution seismic reflection (Williams et al., 1995; Palmer et al., 1997; Van Arsdale et al., 1998) and ground penetrating radar (Bilham, 1985; Cai et al., 1996). In the PALEOSIS project, several methods were applied on each site, with the aim of combining the resolution and penetration characteristics of the different methods (Demanet et al., 2001). 
Field observations, aerial photographs (figure fig. 2) geodetic levelling data and tectonic lineaments (Van den Berg et al., 1994) enabled the identification of the surface expression of the Peel boundary fault. On this basis, two sites (labelled A and B in figure 2) were selected. At site A, the groundwater level was almost equal to the surface and the site was discarded for practical reasons linked to trenching and the very low (two meters) penetration of radar waves. Preliminary tests showed that site $B$ was more suitable and several geophysical techniques were applied across the scarp (figure fig. 2) to find the exact position of the Peel boundary fault and to image the fault zone close to the surface. The investigations included electrical tomography, ground penetrating radar (GPR), seismic reflection profiles and seismic refraction tests (Jongmans, 2000). In this paper we present and interpret the results of the ground penetrating radar and of the electrical tomography near the village of Neer (figure fig. 2), which were the two most successful methods. The investigated zone is a square of about
$100 \mathrm{~m}$ by $100 \mathrm{~m}$ (figure fig. 3) crossed by a little scarp trending NW-SE.

\section{Geophysical prospecting}

Five electrical tomography sections (ET 1 to ET 5 in figure 3) $20 \mathrm{~m}$ apart and eleven ground penetrating radar sections (GPR 1 to GPR 11) $10 \mathrm{~m}$ apart were performed across the Peel boundary fault scarp at Neer.

Electrical tomography permits to obtain a crosssection of the resistivity of the subsurface. The electrical potential $\mathrm{V}$ due to the injection of a current I between two outer electrodes is measured between two inner electrodes. From I and V, the apparent resistivity (the resistivity that a homogeneous soil would have to give the same I and V) is computed with the simple formula $\rho_{\mathrm{a}}=k \mathrm{~V} / \mathrm{I}$, where $k$ is a geometric factor only function of the position of the electrodes (Telford et al., 1990). Depending on the spacing between electrodes and the position of the middle point of the ar-

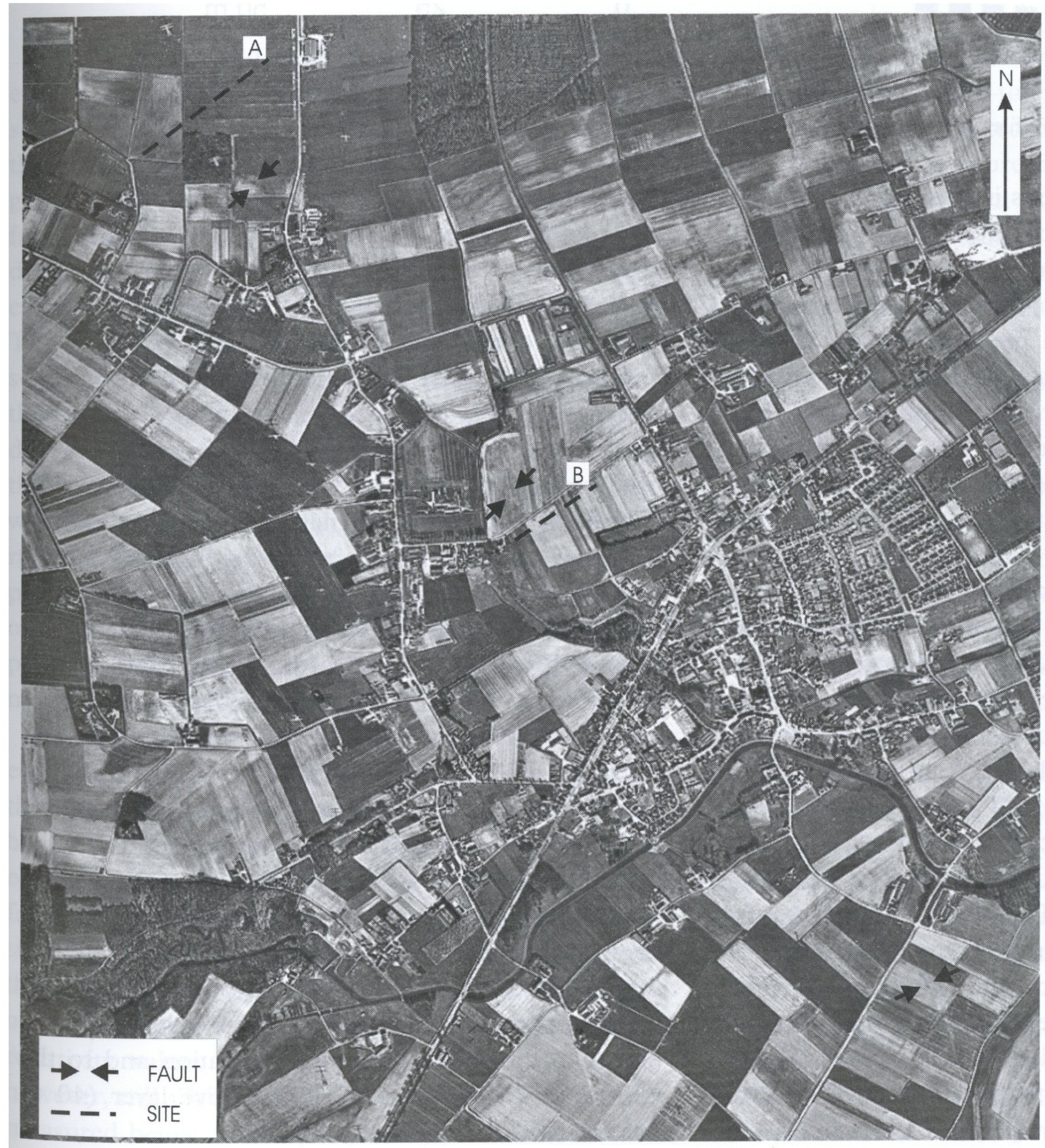

Fig. 2. Aerial photograph of the region of Neer. Indicated are the two investigated sites (A and $\mathrm{B}$ ) by dashed lines, the fault is marked by arrows. 


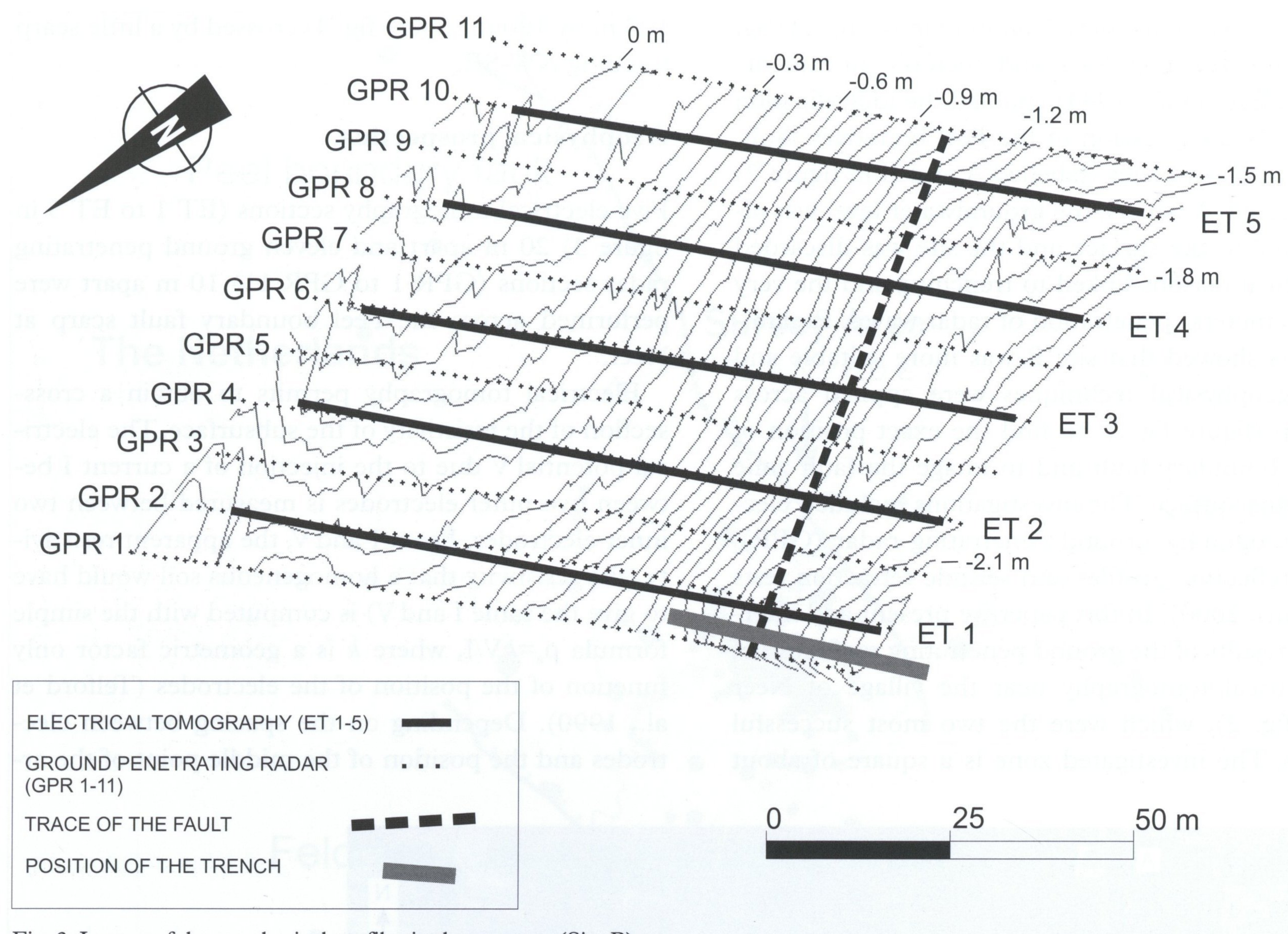

Fig. 3. Layout of the geophysical profiles in the test area (Site B).

ray of electrodes, this value is influenced by different zones of the subsoil. By considering a great number of such data, a complete resistivity cross-section can be retrieved. The collection of the data was automated using the ABEM Lund Imaging system (Dahlin, 1996) with a Wenner configuration and 64 electrodes spaced by $1.5 \mathrm{~m}$. They were processed with the algorithm proposed by Loke and Barker (1996) in order to obtain a resistivity section. According to the profile length of $94.5 \mathrm{~m}$, the investigation depth was around $15-20 \mathrm{~m}$.

In ground penetrating radar (Reynolds, 1997), an electromagnetic impulse is generated and propagates downward into the ground. When it encounters a discontinuity in the dielectric permittivity, some of the energy is reflected back to the surface. The measure is realized by generating a radar pulse and recording the amplitude of the electrical field during a certain time thereafter. The later a reflected wave arrives, the deeper it comes from. In this study, the GPR profiles were performed with a $120 \mathrm{MHz}$ transmitting and receiving antenna. To take into account the non-planar topography, a static correction was made with a mean velocity of $70 \mathrm{~mm} / \mathrm{ns}$ determined from scattered events. The penetration depth, which strongly depends on the ground resistivity, is usually limited to about three meters (two-way travel time of $85 \mathrm{~ns}$ ) with a vertical resolution less than $0.3 \mathrm{~m}$ with the 120 $\mathrm{MHz}$ antenna used. Tests carried out in similar geological conditions with a $500 \mathrm{MHz}$ antenna have given a very low penetration ( $\mathrm{a}$ few $\mathrm{dm}$ ) due to the relatively high conductivity of the fine sand.

Figure $4 \mathrm{~A}$ presents the resistivity section ET5 and the radar profile GPR10 performed at the southern end of the zone. Beyond a depth of 3 meters, the electrical section is characterized by resistivity values lower than $200 \Omega \mathrm{m}$. In the shallow part of the section, two resistive zones (with a resistivity higher than 500 $\Omega \mathrm{m}$ ) occur at a distance around $30 \mathrm{~m}$ and between 62 $\mathrm{m}$ and $90 \mathrm{~m}$ along the profile. The northeastern part of the GPR section shows several slightly SW dipping reflectors down to $3 \mathrm{~m}$ depth, which are flexured and cut at a distance between $62 \mathrm{~m}$ and $66 \mathrm{~m}$. On the contrary, the southwestern block is characterized by horizontal or NE dipping reflectors generating wedges at the contact with the flexured layers.

The two sections are superimposed at the bottom of figure fig. 4A. Both geophysical data sets exhibit anomalies suggesting the presence of a fault at the same position (between $62 \mathrm{~m}$ and $66 \mathrm{~m}$ ). The maximum penetration depth of the radar waves is clearly linked to the vertical resistivity variation and to the presence of an attenuating conductive layer (40 to $200 \Omega \mathrm{m}$ ) below 3 meters. 


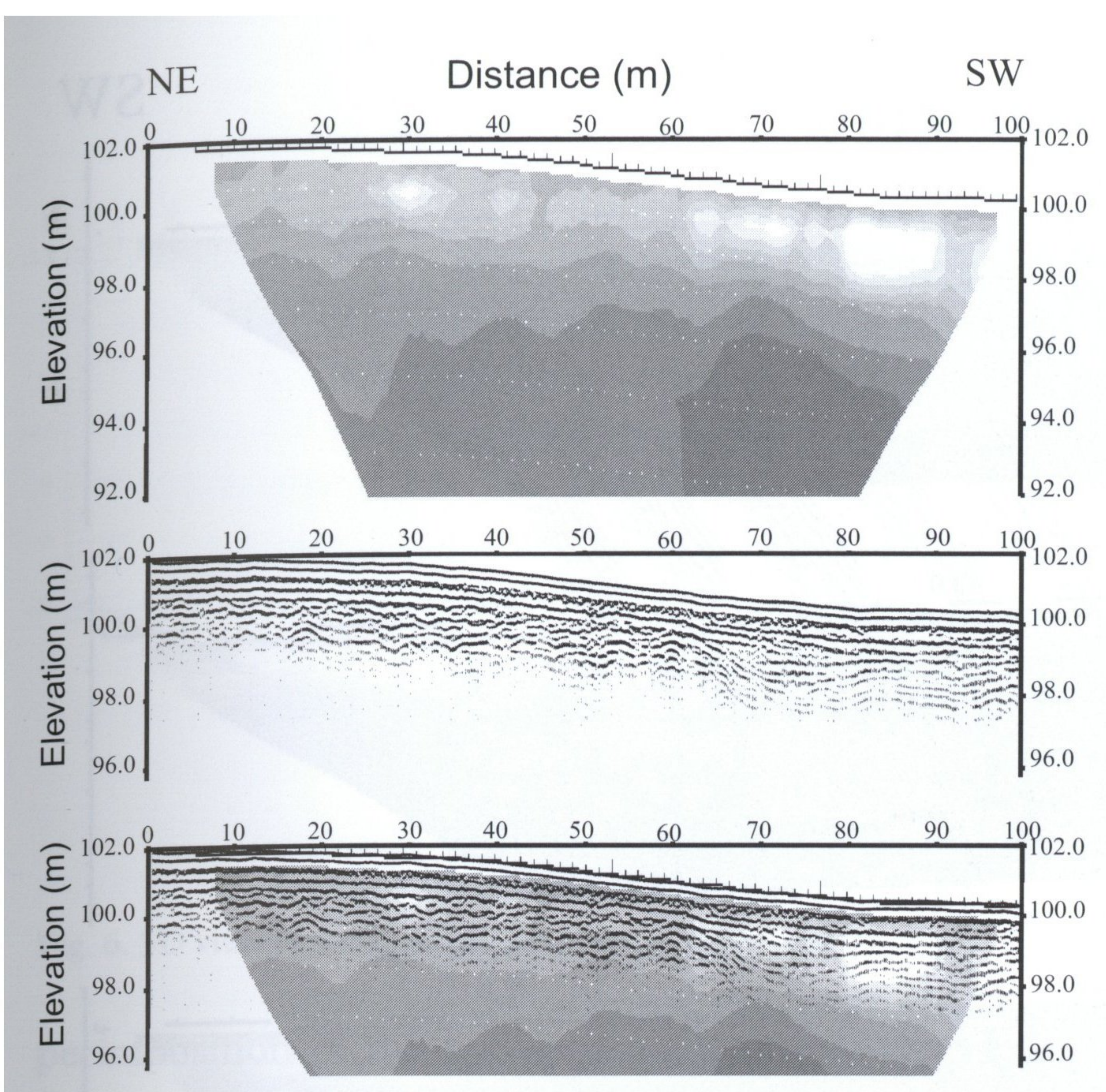

Fig. 4. A: Comparison and superimposition of the resistivity section ET5 and the radar section GPR10. B: Comparison and superimposition of the resistivity section ET1 and the radar section GPR2.

The resistivity and radar sections for the northern end of the zone (sections ET1 and GPR2) are presented in figure $4 \mathrm{~B}$. The same main characteristics, as the ones described for figure $4 \mathrm{~A}$, appear on the two geophysical sections. Comparing to figure $4 \mathrm{~A}$, the fault position is shifted to the SW and located at a distance of $85 \mathrm{~m}$ on the GPR section, while the major contrast is located at $82 \mathrm{~m}$ along the resistivity profile. The resistivity values show that the upper 3 meters of soil in the northeastern block are more homogeneous than along the section ET5. The fault location deduced from geophysical prospecting was checked by the excavation of a trench (location on figure 3) which was described by van den Berg et al. (in preparation). The cross-section of this trench, schematically presented in figure fig. 7, clearly shows the presence of a normal fault at the position defined by the geophysical anomalies with an accuracy less than one meter for the GPR.

The five electrical tomography sections are presented in figure fig. 5 with the same resistivity scale. All the sections are characterised by a strong to moderate horizontal resistivity contrast within the first 3 meters of soil, which approximately traces the location of the fault with an accuracy of a few meters. The five resistivity sections show the regular horizontal shifting of the fault position, from about $72 \mathrm{~m}$ on ET 1 to $62 \mathrm{~m}$ on ET5. At depth, the strong vertical decrease of the resistivity values attenuates this contrast which is, however, still slightly visible. The low resistivity values measured below $3 \mathrm{~m}$ depth probably result from the
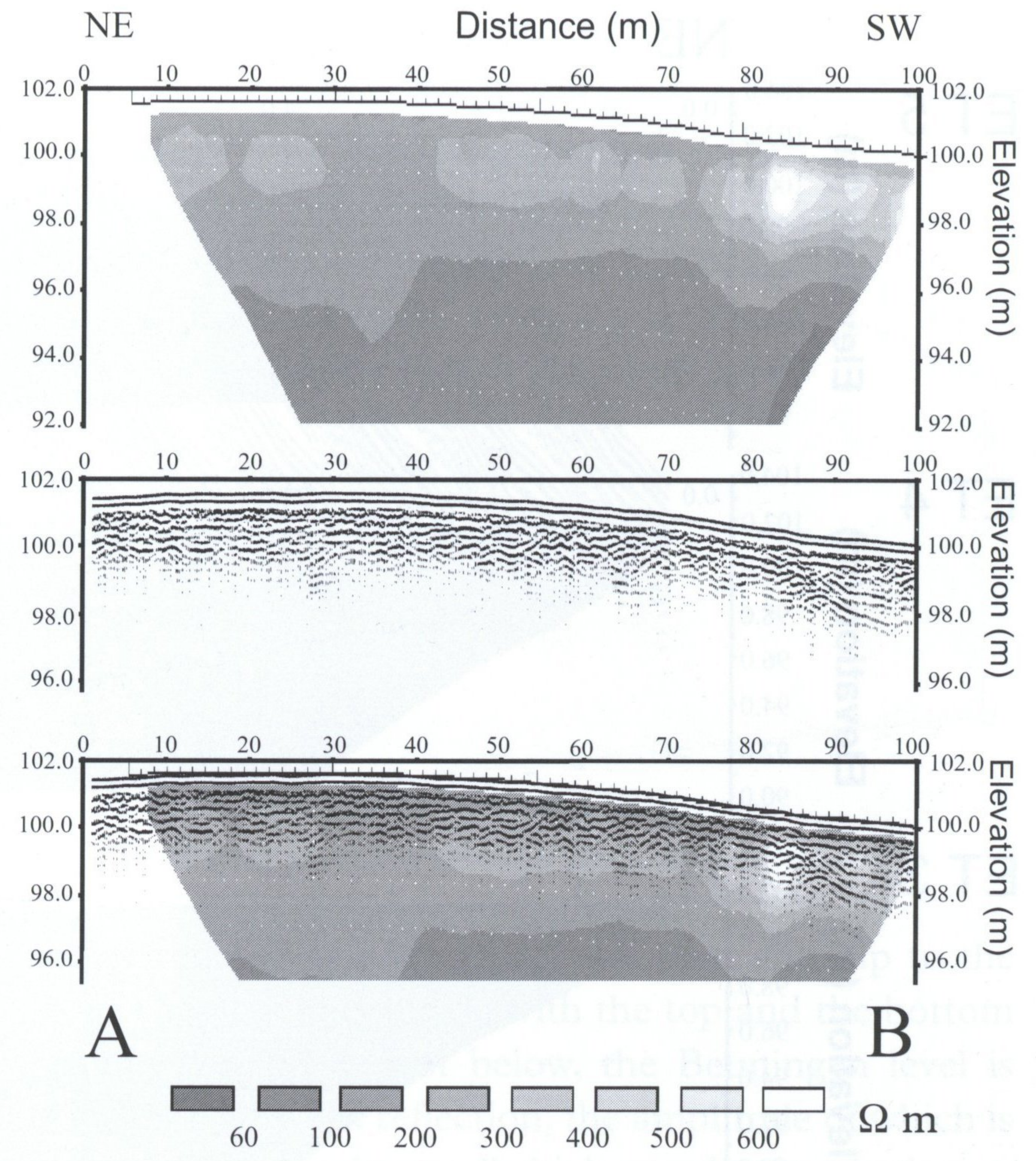

presence of the water table which masks the resistivity contrast observed close to the surface.

A $3 \mathrm{D}$ view constructed from the eleven radar profiles is presented in figure fig. 6. The geometry of the fault can be easily drawn from one section to the other. The trace of the fault at the surface (see figures 6 and 3) approximately follows the scarp, making a small angle with the elevation curves.

\section{Comparison between the trench cross-section and the GPR data}

A $35 \mathrm{~m}$ long trench was excavated perpendicular to the Peel boundary fault. Its location is given in figure fig. 3. A simplified section of the $S$ wall of the trench logged by van den Berg et al. (in preparation) is shown at the top of figure fig. 7. Under the anthropogenic zone (horizons 1 and 2), the first meters of the exposed sediments are composed by fluvial eolian sandy layers more or less silty and locally infiltrated by clay and iron sesqui-oxyde (horizon 4 in the southwestern part of the section). At the top of this sandy formation, an eluvial level (horizon 3), a few decimeter thick, is observed. Within the lower sandy layers (horizon 6), a thin gravel bed (horizon 5 in figure fig. 7) can be recognized. It corresponds to the so-called Beuningen horizon which is approximately 16,000 years old. This gravel bed, at a depth of $0.8 \mathrm{~m}$ in the northeastern part of the section, is flexured and cut by two normal faults with $0.5 \mathrm{~m}$ and $0.3 \mathrm{~m}$ offsets at a distance of about $13 \mathrm{~m}$ along the profile. In the south- 

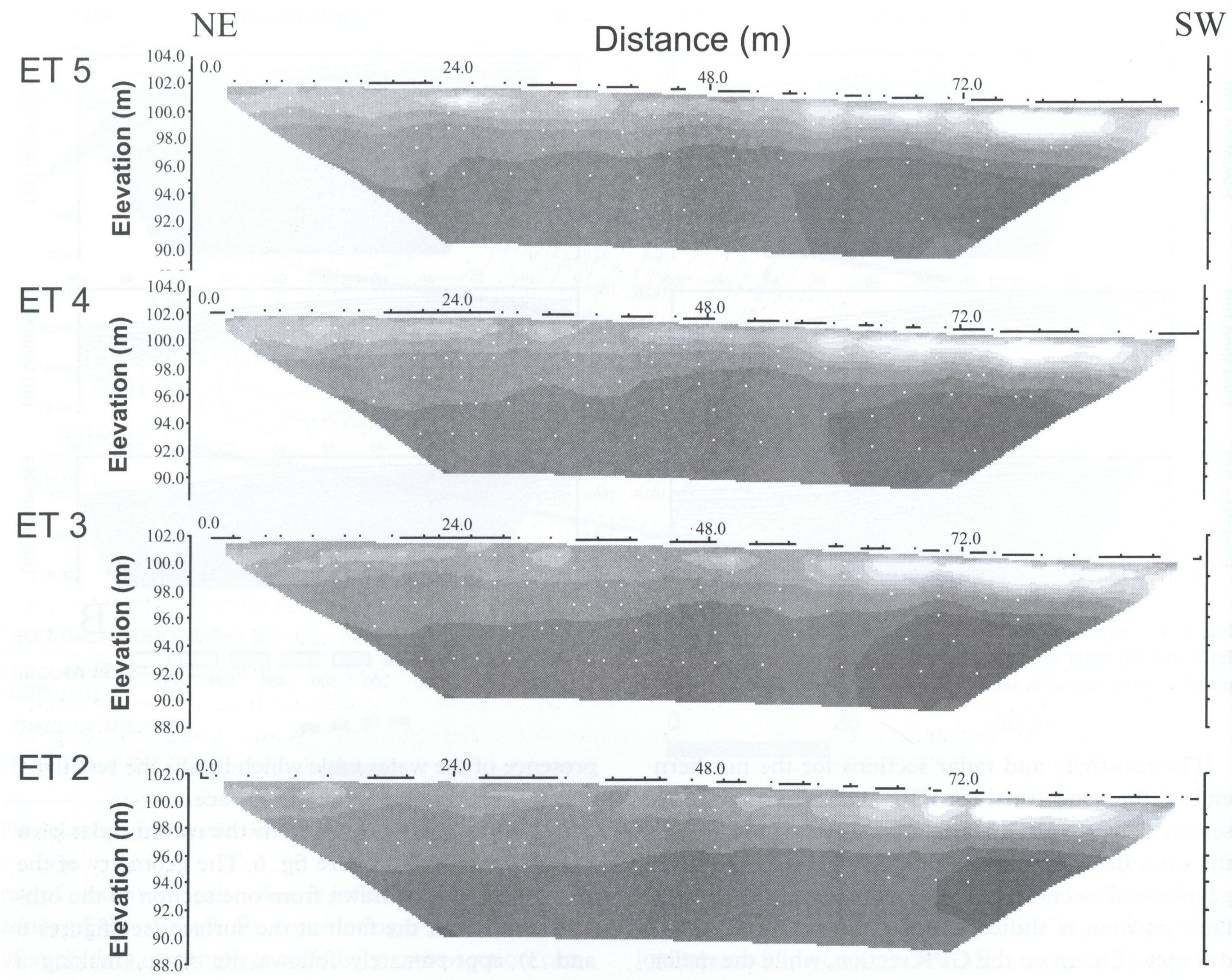

ET 1
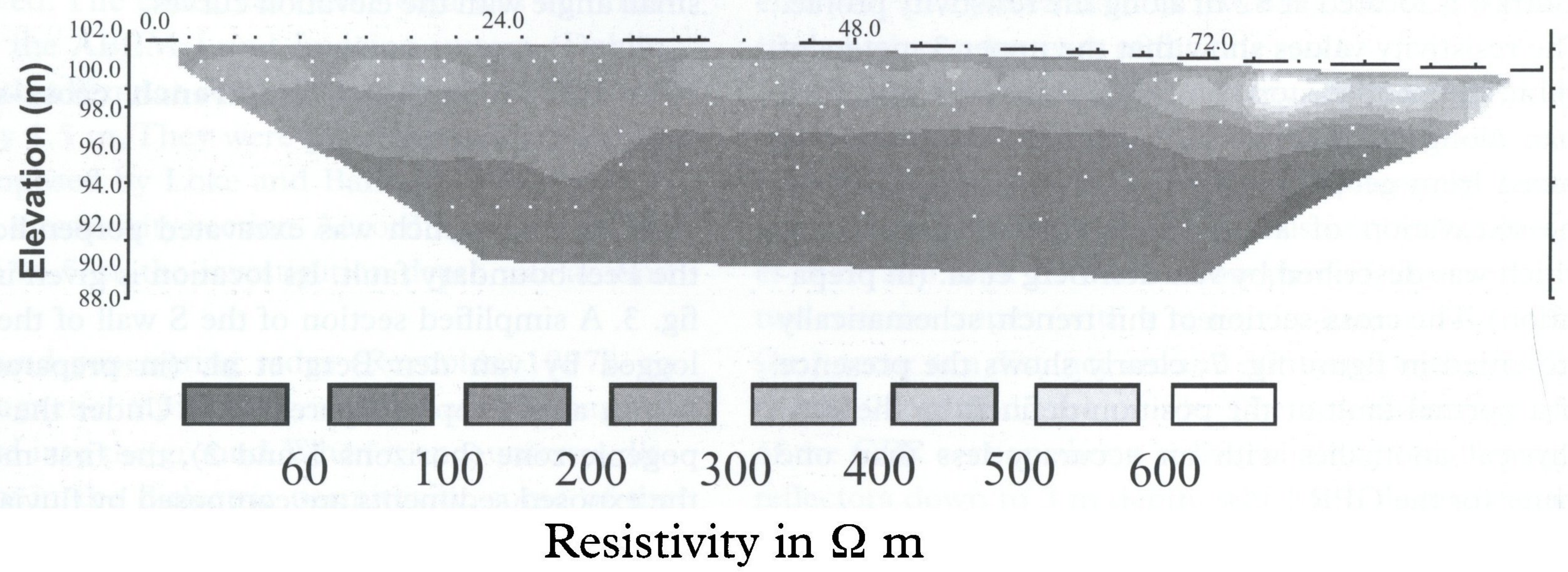

Fig. 5. Electrical tomography profiles.

western part of the section, the Beuningen level is found at a depth of about $2.5 \mathrm{~m}$. At the top of the major fault zone (between $12 \mathrm{~m}$ and $14 \mathrm{~m}$ ) recent movement of $10 \mathrm{~cm}$ along a small and younger fault was found.

The trench $\log$ is compared with the GPR2 radar section in figure fig. 7 in order to define the relations between the reflectors and the geological layers. First, the radar section globally exhibits the same layer structure as the geological section: slightly SW dipping layers in the northeastern block, layer flexuration and offset across the fault zone and flat lying to SW dipping layers in the southwestern block with the presence of a wedge shape near the fault. Also, the structure is much more irregular in the northeastern block than in the southwestern one, in relation with the presence of diffuse sesqui-oxyde and clay infiltration in the former. In the southwestern block, the su- 


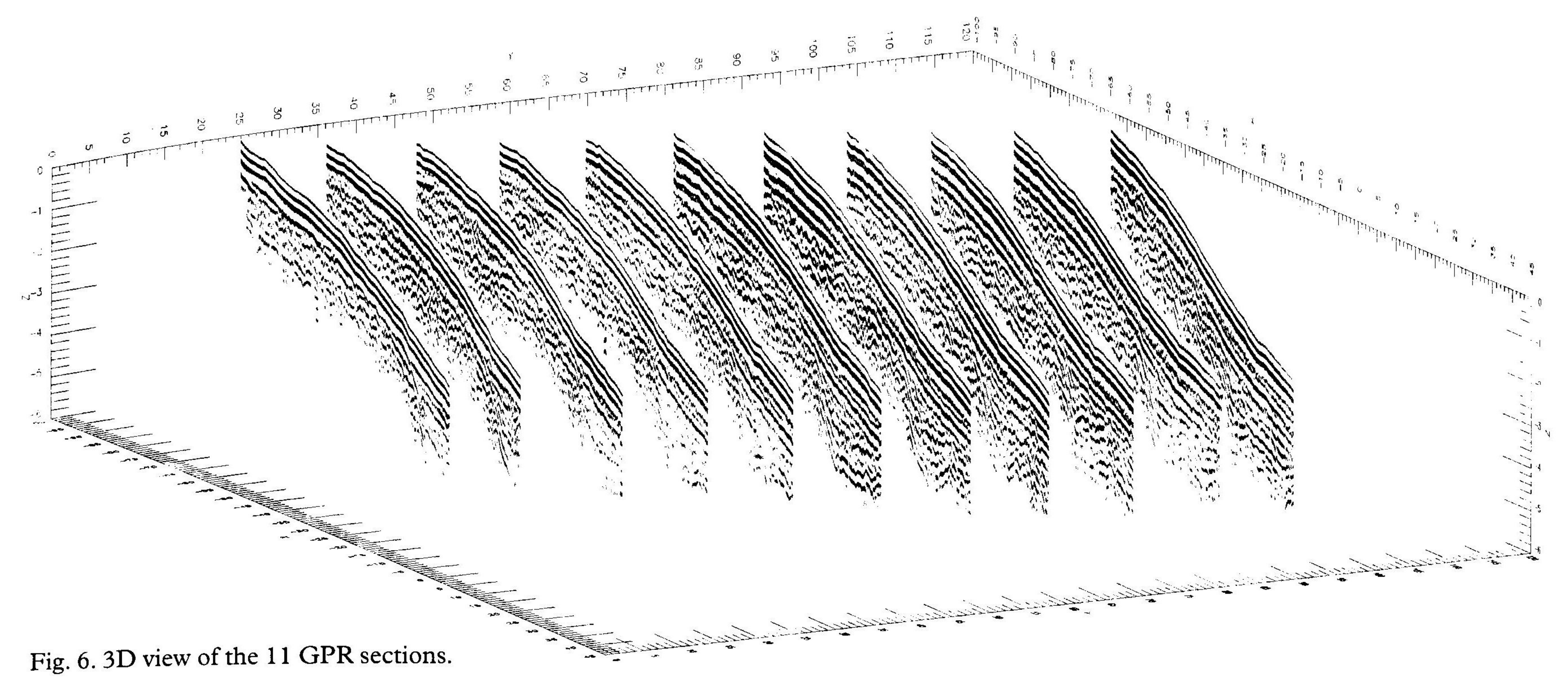

perimposition of the two sections allows to correlate the prominent reflections with geological unconformities. The strong shallow reflection (R1), which is affected by slight disturbances, could correspond to the base of the anthropogenic plough zone. This reflection is present with the same characteristics on all the GPR sections. Just below, another horizontal reflector (R2), which is disturbed to the SW, coincides with the top of the eluvial zone. To the NE this reflector is disrupted at the contact of the fault zone. At greater depth two other reflectors (R3 and R4) are bent and dip to the SW. They could coincide with the top and the bottom of the horizon 4. Just below, the Beuningen level is marked by a weak reflection, the amplitude of which is probably due to its small thickness. In the northeastern block, the reflections are not linked to clear geological unconformities and probably result from the presence of sesqui-oxyde and clay infiltrations.

In figure fig. 8, 6 GPR sections are presented with a tentative interpretation of the structure. The distance

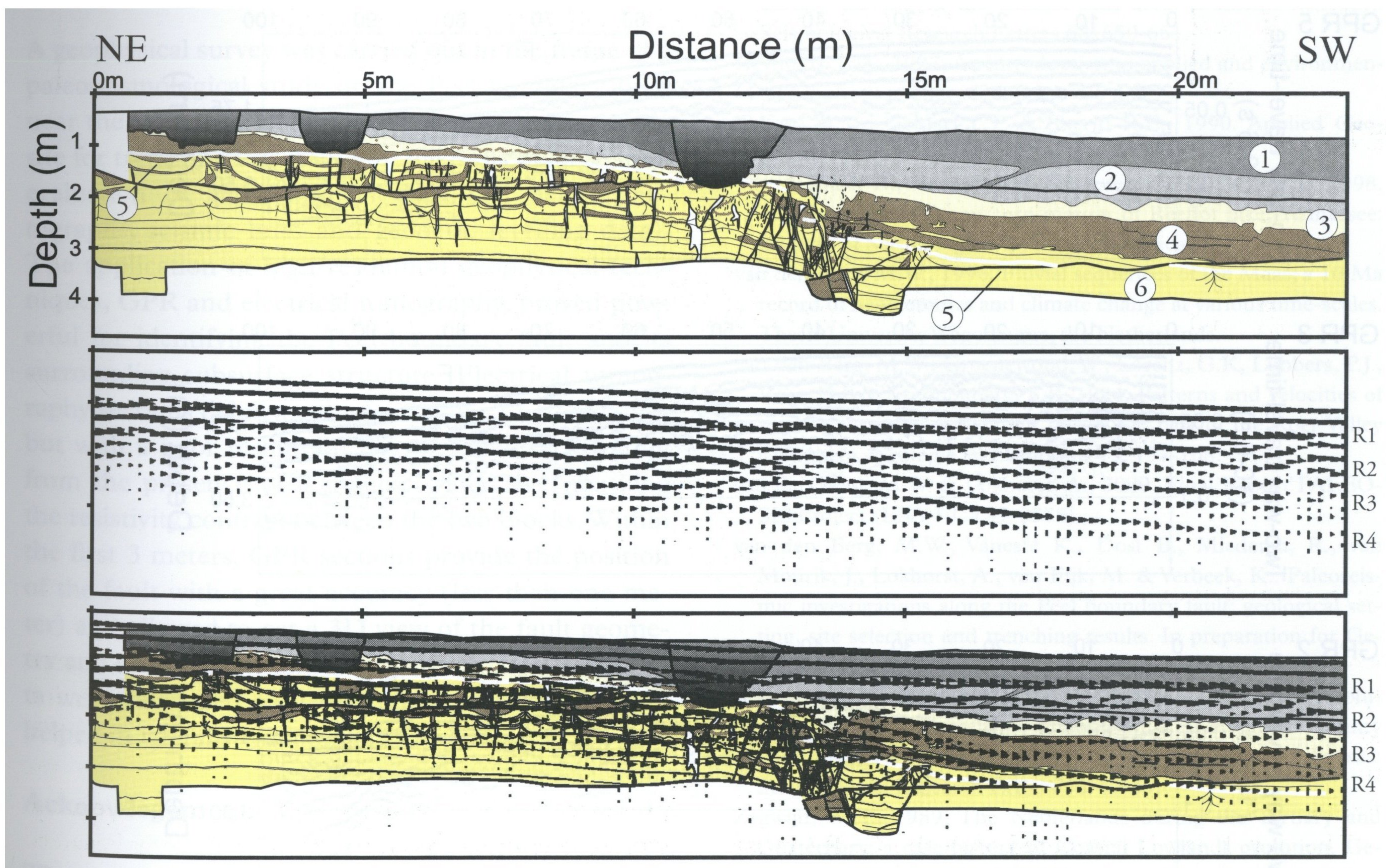

Fig. 7. Comparison of the trench cross-section and the radar section GPR2. Top: trench cross-section (from van den Berg et al., 2001) 1: Antropogenic plough horizon, 2: Transition horizon, 3: Eluvial horizon, 4: Eolian sandy layer with clay and iron sesqui-oxyde, 5: Beuningen gravel bed, 6: Lower sandy layer. Middle: radar section. Bottom: superimposition of the two sections. 

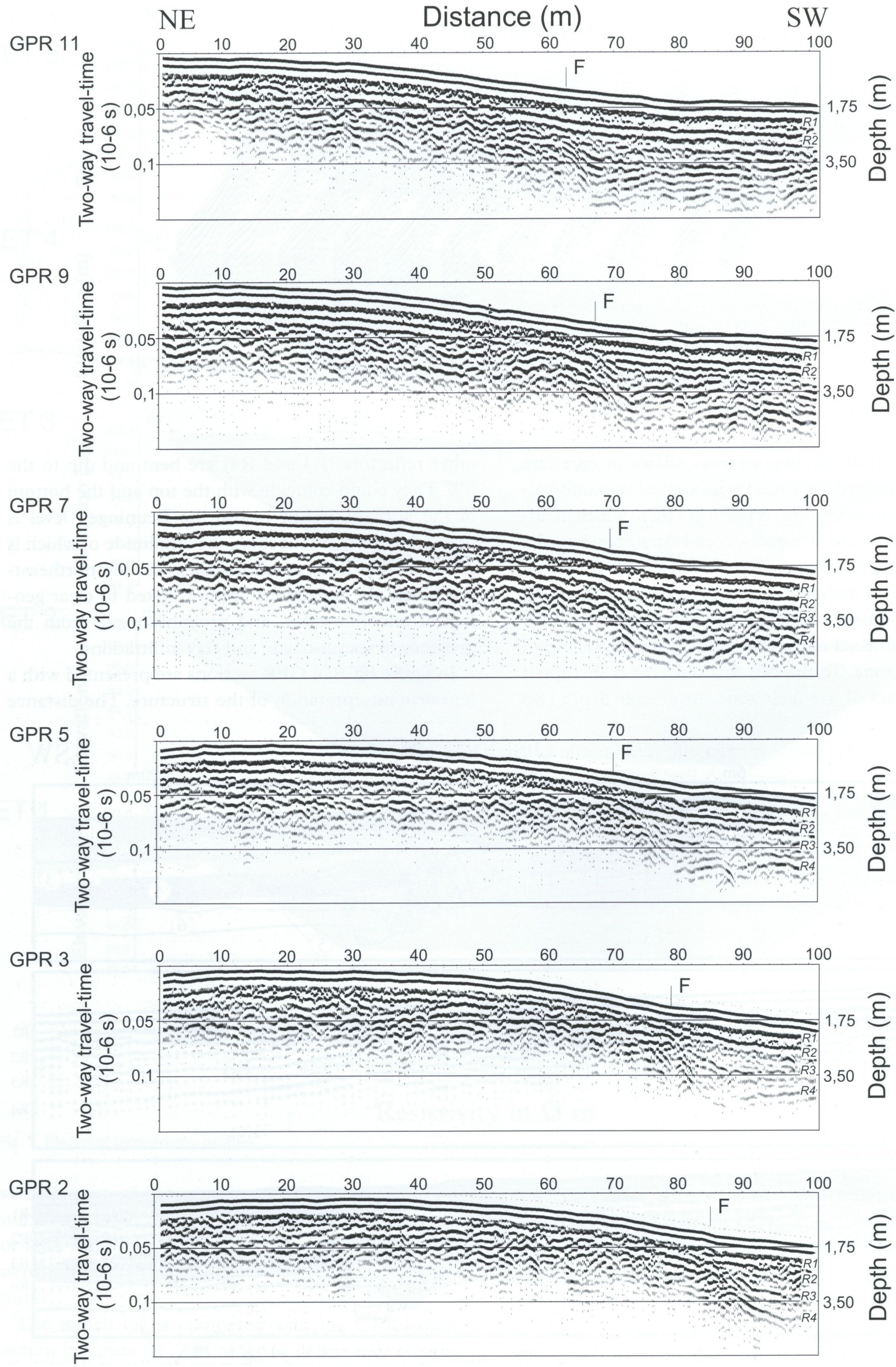

Fig. 8. Interpretation of the GPR profiles. The position of the fault $\mathrm{F}$ is indicated on each section as well as the reflectors $\mathrm{R} 1$ to $\mathrm{R} 4 \mathrm{defined}$ in the text. 
between two successive sections is $20 \mathrm{~m}$, except for sections GPR2 and GPR3 which are $10 \mathrm{~m}$ apart. The fault is clearly located on all the sections as it has already been noticed on the $3 \mathrm{D}$ view (figure fig. 6 ). In the same way, the shallowest disturbed reflector (R1) which limits the plough zone is always visible. On the other hand, all the sections except GPR2 and GPR3 exhibit a relatively continuous double reflection, the upper of which corresponds to the reflector R2 which was shown to coincide with the top of the eluvial horizon along the trench. This double reflection is unaffected by the fault on GPR 11 and is increasingly disturbed from GPR9 to GPR2, which seems to indicate that the eluvial horizon has locally developed after the last ground rupture. Another remarkable feature is the development of a wedge in the southwestern block from GPR2 to GPR1 1 with reflectors dipping to the fault. Within the edge, reflectors R3 and $\mathrm{R} 4$ are difficult to trace along the scarp because of the variation of the reflector number and the scattering. An attempt of following R4 and R3 is presented in figure fig. 8 from GPR2 to GPR7. It shows the very quick lateral variation within the wedge structure. This interpretation should however be calibrated by a new short trench along GPR7.

\section{Conclusions}

A geophysical survey was carried out in the frame of a paleoseismological study on the Peel boundary fault near the village of Neer, The Netherlands. A suitable site for trenching was found on the basis of large scale evaluation of geoscientifical data (i.e. aerial photographs, seismic lines and geodetic levelling data). The application of high resolution geophysical techniques, GPR and electrical tomography, proved powerful for identifying the Peel boundary fault and its surrounding subsurface structure. Electrical tomography sections delineate the fault down to $10 \mathrm{~m}$ depth but with a poor resolution below 3 meters, resulting from the presence of a shallow water level masking the resistivity contrast between the two blocks. Within the first 3 meters, GPR sections provide the position of the fault with a great accuracy (less than one meter) and allowed to get a 3D view of the fault geometry and a detailed insight into the fault zone. GPR data were calibrated with the trench cross-section and helped in laterally extending the trench data.

\section{Acknowlegements}

The authors wish to thank M.W. van den Berg for providing the trench section at Neer. This work was supported by the European Community (Environment program under contract ENV4-CT97-0578).

\section{References}

Bilham, R.L., 1985. Subsurface radar imagery of near-surface fractures associated with the Borah Peak earthquake, Idaho. Proceedings of the workshop XXVIII on the Borah Peak, Idaho earthquake: 182-194.

Cai, J., Mcmechan, A. \& Fisher, M.A., 1996. Application of ground penetrating radar to investigation of near-surface fault properties in the San Francisco bay region. Bulletin of the Seismological Society of America 86: 1459-1470.

Dahlin, T., 1996. 2D Resistivity surveying for environmental and engineering applications. First Break 14: 275-283.

Demanet D., Renardy F., Vanneste K., Jongmans D., Camelbeeck T. \& Meghraoui M., 2001. The use of geophysical prospecting for imaging active faults in the Roer graben, Belgium. Geophysics 66: 78-89.

Geluk, M.C, Duin, E.J.Th., Dusar, M., Rijkers, R.H.B., Van den Berg, M.W. \& Van Rooijen P., 1994. Stratigraphy and tectonics of the Roer Valley Graben. Geologie en Mijnbouw 73: 129-141.

Jongmans D., 2000. Development and application of geophysical prospecting for fault detection and characterization purposes. Final Report PALEOSIS Project (ENV4-CT97-0578).

Loke M.H., \& Barker, R.D., 1996. Rapid least-squares inversion of apparent resistivity pseudosections by a quasi-Newton method. Geophysical Prospecting 44: 131-152.

Palmer, J.R., Shoemaker, M., Hoffman, D., Anderson, N.L., Vaughn, J.D. \& Harrison, R.W., 1997. Seismic evidence of quaternary faulting in the Benton hills area, southeast Missouri. Seismological Research Letters 68: 650-661.

Reynolds, J.M., 1997, An introduction to applied and environmental geophysics: Wiley, Chicester, $796 \mathrm{p}$.

Telford W.M., Geldart L.P. \& Sheriff R.E., 1990. Applied Geophysics : Cambridge University Press, $770 \mathrm{p}$.

Van Ardsale, R., Purser, J., Stephenson, W. \& Odum, J., 1998. Faulting along the southern margin of Reeflot lake, Tennessee: Bulletin of Seismological Society of America 88: 131-139.

van den Berg, M.W., 1996, Fluvial sequences of the Maas; a $10 \mathrm{Ma}$ record of neotectonics and climate change at various time-scales. Thesis University Wageningne, the Netherlands.

van den Berg, M.W., Groenewoud, W., Lorenz, G.K, Lubbers, P.J., Brus, D.J. \& Kroonenberg, S.B, 1994. Patterns and velocities of recent crustal movements in the Dutch part of the Roer Valley rift system. Geologie en Mijnbouw 73: 157-168.

van den Berg, M.W. \& Lokhorst, A., 2000. Final Report PALEOSIS Project (ENV4-CT97-0578).

van den Berg, M.W., Vaneste K., Dost B., Miedema, R., van Mourik, J., Lokhorst, A., van Eijk, M. \& Verbeek, K.. Paleoseismic investigations along the Peel boundary fault: geological setting, site selection and trenching results. In preparation for Geologie en Mijnbouw.

Williams, R. A., Luzietti, E.A. \& Carver, D.L., 1995, High-resolution imaging of Quaternary faulting on the Crittenden County fault zone, New Madrid seismic zone, northeastern Arkansas: Seismological Research Letters 66: 42-57.

Zagwijn, W.H., 1989. The Netherlands during the Tertiary and Quaternary: a case history of Coastal Lowlands evolution. Geologie en Mijnbouw 68: 107-121. 